\title{
THE UREA GLEARANGE TEST IN CHILDREN
}

\author{
BY \\ W. W. PAYNE AND H. SHUKRY. \\ (From the Hospital for Sick Children, Great Ormond Street, London.)
}

The value of the urea clearance test in the estimation of renal function is now well established. It was thought advisable before using it as a routine at this hospital to check the normal response in children with that of the adult and to compare the results of the test with the one previously in use (McLean's urea concentration test). The increase in the minute volume of the urine as a result of applying the surface area correction is considerable and might well invalidate results based on adult values. A good discussion of the underlying principle of the test is given by Peters and van Slyke ${ }^{1}$ but a brief mention of it is made here.

It has been found that if the kidneys are excreting more than a certain volume per minute (the augmentation limit-about 2 c.c. in the adult) the amo:ant of urea excreted bears a constant ratio to the blood urea irrespective of the volume of the urine. Thus with a constant blood urea a constant amount of urea is excreted every minute. In other words a constant volume of blood may be conceived as giving up all its urea. This volume of blood is calculated to be 75 c.c. per minute, and is the 'maximal clearance value' in the adult.

If the kidneys are excreting less than this volume of urine, it is found that the amount of urea excreted is affected by the volume of urine as well as by the blood urea, and it has been found that the quantity of urea varies approximately as the square root of the minute volume of the urine. Thus if 75 c.c. of blood are cleared with a minute volume of 2 c.c. then $75 \times \frac{\sqrt{1}}{\sqrt{2}}$ c.c. $(53 \cdot 1$ c.c.) of blood should be cleared with a minute volume of 1 c.c. Experimentally 54 c.c. is found to be the average value and this figure is taken as the 'standard clearance value' for the standard of comparison whenever the minute volume fails to exceed 2 c.c.

It is obvious, however, that both the blood and urine volume will vary with the size of the subject and a correction depending on the surface area is used so as to bring the excretion rate into comparison with the normal.

In performing the test it is more satisfactory to obtain the maximum clearance value. This is not always possible but the standard clearance value can always be determined. The maximum value is obtained by giving a dose of urea and large quantities of fluids some two to four hours before starting the collection of urine. At an accurately noted time the subject empties the bladder and at the end of about one hour the bladder is again emptied and the time noted. All the urine passed in this period is kept and measured. Blood for urea determination is taken as near the middle of the period as possible. A second hour period with a second blood urea is advisable. 
In obtaining the standard value no preliminary preparation is required. The urine is collected as above and the blood urea estimated. It is not usually necessary to take a second blood test since no variation occurs in our experience within one hour unless urea or much fluid had been taken previously. The only precaution in the preparation of the patient is the avoidance of diuretics in the previous meal such as tea, coffee or alcohol. The height and weight of the subject must be taken accurately.

For the analysis we have used Archer's urease method ${ }^{2}$ for blood and McLean's modification of the hypobromite method $^{3}$ for urine. As a check the urease method for urine has been used but no differences of clinical importance between the two methods were found.

Calculation.-The surface area is first obtained, either from tables or from Du Bois' formula : $\mathbf{A}=\mathbf{H}^{0.735} \times \mathbf{W}^{0.425} \times \mathbf{7 1 . 8 4}$, where $\mathbf{A}=$ surface area in sq. $\mathrm{cm}$., $\mathbf{H}=$ height in $\mathrm{cm}$. and $\mathbf{W}=$ weight in $\mathrm{kgm}$. The average adult surface area is taken as 1.73 sq. metres.

The corrected urine minute volume (Vc) is found thus:-

$$
V_{c}=\frac{\text { Volume of urine passed per minute }}{\text { Surface area in sq. metres. }} \times 1.73
$$

If the value of $\mathrm{Vc}$ is above 2 the 'maximum clearance' (M) is found from the following formula :-

$$
M=\frac{\text { mgm. urea per } 100 \text { c.c. urine }}{\text { mgm. urea per } 100 \text { c.c. blood. }} \times \text { Vc }
$$

The average for adults is 75 .

If the value of Vc is under 2 the 'standard clearance' (S) is obtained as under :-

$$
\mathrm{S}=\frac{\text { mgm. urea per } 100 \text { c.c. urine }}{\text { mgm. urea per } 100 \text { c.c. blood. }} \times \sqrt{\mathrm{Vc}}
$$

The average for adults is 54 .

In practice it is convenient to express results as a percentage of the corresponding average value. Most normal cases fall between 80 per cent. and 120 per cent. A considerable variation can be expected and indeed is normal, but consecutive results below 80 per cent. can be taken in the adult as abnormal.

\section{Results.}

Thirty-nine children suffering or convalescent from diseases not involving the renal tract were examined. The urine was tested and was normal in all but one patient who was passing albumin. He was a patient with haemophilia with no history of renal involvement. Table 1 gives a summary of the results expressed as percentage of the adult normal. It is apparent from this that the average for children is higher than that for the adult and also that the zone into which most cases fall is also greater (80-140 as against 80-120). Inasmuch as once the kidney has passed the minimal threshold it is regarded as normal, the upper limit has no great clinical interest, and since the lower limit coincides with the adult value it has not been deemed advisable to use a different normal for children, 
In examining the results applied to individual cases no normal case failed to exceed in at least one test the minimal value, but one subject gave four results-all ' standard' values, three of which were below 80 per cent., and this must be considered to be a ' doubtful' result.

TABLE 1.

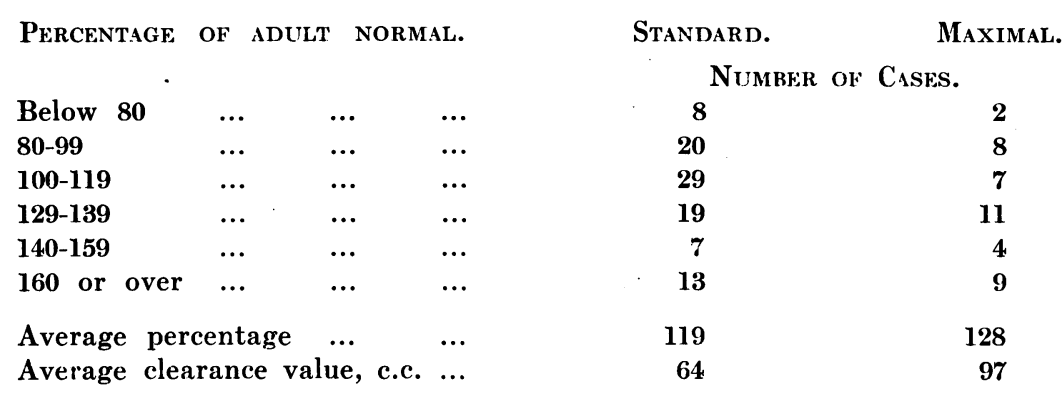

McLean's test was applied to the same group and in all but one values over 2.5 per cent. urea were obtained in one or more specimen indicating a normal function. In the one failure the highest value was $2 \cdot 4$ per cent. and this was the case of haemophilia referred to above. Both tests thus give a satisfactory response with the normal.

TABLE 2.

Disease.

Ac. haemorrhagic nephritis

$\begin{array}{lccc} & \text { Standard. } & \text { Maximal. } & \text { McLean. } \\ \ldots & \mathbf{N} & - & \mathbf{N} \\ \ldots & \mathbf{N} & - & \mathbf{N} \\ \ldots & \mathbf{D} & \mathbf{D} & \mathbf{N} \\ \ldots & \mathbf{D} & \mathbf{A} & \mathbf{N} \\ \ldots & \mathbf{D} & \mathbf{A} & \mathbf{N} \\ \ldots & \mathbf{A} & \mathbf{A} & \mathbf{N} \\ \ldots & \mathbf{A} & \mathbf{A} & \mathbf{A} \\ \ldots & \mathbf{A} & \mathbf{A} & \mathbf{N} \\ \ldots & \mathbf{A} & \mathbf{A} & \mathbf{A} \\ \ldots & \mathbf{A} & \mathbf{N} & \mathbf{D} \\ \ldots & \mathbf{N} & \mathbf{N} & \mathbf{N} \\ \cdots & \mathbf{A} & \mathbf{A} & \mathbf{N} \\ \cdots & \mathbf{D} & \mathbf{A} & \mathbf{N} \\ \mathbf{D} & \mathbf{D} & \mathbf{D}\end{array}$

Bismuth nephritis $\quad \ldots \quad \ldots \quad \ldots \quad$ A

Chronic nephritis $\quad \ldots \quad \ldots \quad \ldots \quad$ A

$\begin{array}{ccccc}\dddot{ } & & \ldots & \ldots & \text { A } \\ \text { Pyelonephritis } & \ldots & \ldots & \ldots & \text { N }\end{array}$

Bilateral hydronephrosis $\ldots \quad \ldots \quad \ldots \quad$ A

Pyelitis and nephrectomy $\quad \ldots \quad$ D

$$
\mathbf{N}=\text { Normal, } \mathbf{D}=\text { Doubtful, } \mathbf{A}=\text { Abnormal. }
$$

Another group of thirteen children suffering from some disease involving the kidney were examined by each test. The results are summarized in table 2. It will be seen that in this small series of pathological cases the agreement between the results ceases to be good. There is no great difference between the two clearance tests, but in three cases doubtul results according to the ' standard' test are definitely abnormal in the ' maximal' test. McLean's concentration test gives normal results in six cases in which the maximal test gives an abnormal response. It is apparent therefore that the capacity of the kidney to excrete urea decreases earlier in disease than the capacity to concentrate urea in the urine. 
While admitting that the numbers are small the results are so definite that the conclusion may be drawn that the urea clearance test is more likely to detect early loss of kidney function than is McLean's concentration test. Brief mention may be made of three applications of this method.

Effect of anaesthetics.-Six subjects who were not suffering from renal or septic conditions were examined by the maximal clearance test as soon as possible after an anaesthetic had been given. Ether and nitrous oxide were used in all cases and the duration was from ten to thirty minutes. The blood urea was found to be raised but the clearance was normal. Repeated in ten days time all the tests were normal including the blood urea. The conclusion may be drawn that the post-operative rise in blood urea is not due to failure of renal excretion.

Nephrectomy.-Two patients have been examined after nephrectomy. The first case four months after the operation gave a normal concentration test but failed to give a normal maximal clearance test. It was thought that perhaps the remaining kidney had not hypertrophied sufficiently to be able to clear as much blood urea as two normal kidneys while still being able to concentrate urea. The kidney was removed for chronic pyelitis and was functioning before removal. The second kidney was only slightly infected but may not have been quite normal. The second patient was examined two weeks after the operation and gave a normal maximal clearance. The kidney was removed for sarcoma and possibly had been relatively functionless for some time before its removal.

' Nephrosis.'-A good example of this syndrome was examined by both the clearance techniques and by McLean's method. It was not possible to get a sufficient flow of urine to pass the augmentation limit but the standard clearance was normal as also was the concentration test.

\section{Summary.}

The renal function in two groups, one normal and the other pathological, has been examined by the maximal and standard clearance tests and by the urea concentration test. No difference was found between the results of the different methods in the normal group but in the pathological group the results differed. The order of sensitivity was: maximal clearance, standard clearance, urea concentration.

The effect of anaesthetics (ether-nitrous oxide) has been examined. No change in the kidney function was detected.

Our thanks are due to the honorary medical and surgical staff of the Hospital for Sick Children for permission to investigate children under their care.

\section{REFERENGES.}

1. Peters, T. B., \& Van Slyke, D. D., Quantitive Clinical Chemistry, London, 1931.

2. Twort, C. C., \& Archer, H. E., Lancet, London, 1923, i, 1102.

3. McLean, H., Mod. Methods in the Diag. and Treat. of Renal Dis., London, 1927, 